\title{
Phaeochromocytoma and functioning paraganglioma in childhood and adolescence: role of iodine 131 metaiodobenzylguanidine
}

\author{
Frederick A. Khafagi', Brahm Shapiro ', Manfred Fischer *, James C. Sisson ${ }^{1}$, \\ Raymond Hutchinson ${ }^{2}$ and William $\mathrm{H}$. Beierwaltes ${ }^{1}$ \\ 1 Division of Nuclear Medicine, Department of Internal Medicine, B1G 412 University Hospital, and \\ ${ }^{2}$ Division of Hematology/Oncology, Department of Pediatrics, University of Michigan Medical Center, Ann Arbor, Ml 48109-0028 \\ USA
}

Received 1 October and after revision 20 October 1990

\begin{abstract}
Phaeochromocytomas and functioning paragangliomas are rare tumours in childhood and adolescence. We review our experience of 43 cases ( $24 \mathrm{men}$, 19 women) who were first diagnosed at the age of $\leq 18$ years. All patients were evaluated at some point in their illness with iodine 131 metaiodobenzylguanidine $\left({ }^{131} \mathrm{I}-\mathrm{mIBG}\right)$ scintigraphy. Eight patients $(19 \%)$ had bilateral adrenal tumours, $12(28 \%)$ had solitary extraadrenal tumours, and $8(19 \%)$ had multiple tumours. In 10 patients $(23 \%)$, the tumours were associated with a familial neurocristopathic syndrome. Thirteen of 24 $(54 \%)$ unifocal tumours which were initially considered to be benign ultimately proved to be multi-focal and/or malignant. The final prevalence of malignancy was $60 \%$ - 26 patients, of whom only $15(57 \%)$ had obviously malignant tumours at the time of diagnosis. Primary tumour size $\geq 5 \mathrm{~cm}$ was more commonly associated with a malignant course in adrenal but not extra-adrenal tumours. No other clinical, biochemical or morphological characteristic was significantly associated with malignancy. Although the high prevalence of malignancy in this series at least partly reflects referral bias, the need for lifelong follow-up of these patients is underscored. ${ }^{131} \mathrm{I}$-mIBG scintigraphy was positive in 36 patients $(84 \%)$, with a somewhat lower false-negative rate $(12 \%)$ than X-ray computed tomography $(20 \%)$. Eight patients with malignant tumours received therapeutic doses of ${ }^{131} \mathrm{I}-\mathrm{mIBG}$, with partial tumour responses in 3. Thus, ${ }^{131} \mathrm{I}$-mIBG is an efficacious, non-invasive, localising agent and may be considered as a palliative therapeutic agent when alternatives have failed.
\end{abstract}

Key words: Phaeochromocytoma - Paraganglioma Childhood - Adolescence - Metaiodobenzylguanidine

\footnotetext{
* Current address: Department of Nuclear Medicine, Städtische Kliniken, Kassel, Federal Republic of Germany
}

Offprint requests to: $\mathrm{B}$. Shapiro
Eur J Nucl Med (1991) 18:191-198

\section{Introduction}

Phaeochromocytomas are catecholamine-secreting tumours arising from adrenal medullary tissue which produce a highly variable clinical syndrome typically characterised by the triad of hypertension, headache and sweating (Manger and Gifford 1982; Bravo and Gifford 1984; Shapiro and Fig 1989). Hypercatecholaminaemia and an identical syndrome may also result from functioning tumours arising in extra-adrenal chromaffin tissue within sympathetic and other autonomic ganglia and paraganglia (including such specialised structures as the carotid and aortic bodies); such tumours have variously been termed "extra-adrenal phaeochromocytomas" and "functioning paragangliomas" - the latter designation has been recommended by the Armed Forces Institute of Pathology (Glenner and Grimley 1974).

Phaeochromocytomas and functioning paragangliomas are rare tumours, with an estimated prevalence of $0.1 \%-0.5 \%$ of the hypertensive population and a peak incidence in the 3rd to 4th decades (Manger and Gifford 1982; Bravo and Gifford 1984; Shapiro and Fig 1989). It is generally held that approximately $10 \%$ of tumours are extra-adrenal, $10 \%$ of patients have multiple tumours, $10 \%$ of tumours are malignant, and $10 \%$ occur in childhood. Although the reported incidence of malignant tumours in childhood appears to be similar to that in adults, over $50 \%$ of children with the phaeochromocytoma syndrome have extra-adrenal, bilateral adrenal or multiple tumours (Hume 1960; Stackpole et al. 1963; Melicow 1977; Kaufman et al. 1983). Phaeochromocytomas and functioning paragangliomas are components of the autosomal dominant multiple endocrine neoplasia 
(MEN) syndromes types $2 a$ (medullary thyroid carcinoma, parathyroid hyperplasia or adenoma and phaeochromocytoma) and $2 b$ (marfanoid habitus, mucosal neuromata, medullary thyroid carcinoma and phaeochromocytoma and may occasionally appear in isolation as an autosomal dominant familial syndrome without other features of MEN (Glowniak et al. 1985). They are also associated with the neurocutaneous syndromes of von Recklinghausen's (neurofibromatosis) and Lindauvon Hippel disease (retinal and cerebellar angiomatosis and multiple hamartomas) more commonly than in the general population. Finally, paragangliomas may occur in association with gastric leiomyosarcomas and pulmonary chondromas to make up Carney's triad (Carney 1983). In all these syndromes, affected children are disproportionately over represented. Because of the rarity of the phaeochromocytoma syndrome in the paediatric and adolescent age group, series reported from single institutions are necessarily small. We present the combined experience of two tertiary referral centres in evaluating patients whose original tumours were diagnosed in childhood.

\section{Patients and methods}

In this retrospective study, patients in whom the diagnosis of (adrenal) phaeochromocytoma or functioning paraganglioma (extra-adrenal phaeochromocytoma) was made at or before the age of 18 years were identified from our data base of patients referred to the University of Michigan Medical Center, Ann Arbor, Michigan, or the University of Munster, FRG, for evaluation with iodine 131 metaiodobenzylguanidine $\left({ }^{131} \mathrm{I}-\mathrm{mIBG}\right)$ in the 5 years ending December 1985. (After 1985, the more widespread availability of $\mathrm{mIBG}$ outside these institutions resulted in a change in our referral base.) All studies were performed with the written consent of the patients or their legal guardians, according to protocols approved by the institutions' research ethics committees.

Upon referral, a history was taken and a physical examination performed with all patients, with particular attention to family history or clinical evidence of familial syndromes including MEN and neurocutaneous syndromes. Blood samples were collected for the measurement of plasma catecholamine (adrenaline and noradrenaline) levels in resting, supine, fasted patients through an indwelling intravenous cannula which had been inserted at least $30 \mathrm{~min}$ before sampling. Plasma catecholamines were measured by a radioenzymatic assay (Peuler and Johnson 1977). The 12- or 24-h urinary catecholamine and metanephrine (metanephrine and normetanephrine) levels were determined by a fluorimetric assay (Von Euler and Lishajko 1959), and urinary vanillylmandelic acid (VMA) levels were measured spectrophotometrically (Pisano et al. 1962).

Prior to ${ }^{131} \mathrm{I}-\mathrm{mIBG}$ scanning, all patients received three drops of a saturated solution of potassium iodide (SSKI, $120 \mathrm{mg}$ iodide) per day for 1 week starting from the day before injection to block thyroidal uptake of free radioiodide. ${ }^{131} \mathrm{I}-\mathrm{mIBG}$ [specific activity $48 \mathrm{GBq}(1.3 \mathrm{Ci}) / \mathrm{mmol}$ ] was given by slow intravenous injection in a dose of $18.5 \mathrm{MBq}(0.5 \mathrm{mCi}) / 1.73 \mathrm{~m}^{2}$ body surface area, to a maximum dose of $37 \mathrm{MBq}(1.0 \mathrm{mCi})$. At 24,48 and $72 \mathrm{~h}$ after injection, overlapping scintigrams of the whole body were obtained using a wide field-of-view gamma-camera fitted with a high-energy, parallel-hole collimator and interfaced to a computer. Images were acquired for 100000 counts or $20 \mathrm{~min}$ per view. All scans were reported by experienced observers according to criteria previously described (Nakajo et al. 1983; Shapiro et al. 1985). The location of areas of abnormal uptake was defined by using external surface markers or, when necessary, "internal markers" in the form of ${ }^{99 \mathrm{~m}} \mathrm{Tc}$-labelled radiopharmaceuticals or ${ }^{201} \mathrm{Tl}$. Therapeutic doses of ${ }^{131} \mathrm{I}-\mathrm{mIBG}$ [specific activity $300-400 \mathrm{GBq}(8-11 \mathrm{Ci}) / \mathrm{mmol}$ ], administered to patients with malignant disease unreponsive to other modalities, were based on dosimetric calculations made with a "tracer" dose of $37 \mathrm{MBq}(1.0 \mathrm{mCi}) / 1.73 \mathrm{~m}^{2}$ of body surface area and external standard sources (Shulkin et al. 1988).

Statistical comparisions were carried out using the unpaired Student's $t$ test or the Mann-Whitney $\mathrm{U}$ test and the $\chi^{2}$ test; correlations were by simple linear regression. Statistical significance was accepted at the $5 \%$ level.

\section{Results}

Among 206 patients of all ages known or subsequently proven to have phaeochromocytomas or functioning paragangliomas referred to the University of Michigan or University of Munster in the period 1980-1985 for evaluation with ${ }^{131} \mathrm{I}-\mathrm{mIBG}, 43(21 \%)$ had their initial diagnoses made at the age of 18 years or younger (Fig. 1). Some of these patients have been the subjects of earlier individual case reports (Shapiro et al. 1984; Glowniak et al. 1985; Imperato-McGinley et al. 1987; Shulkin et al. 1987). The median age at initial presentation was 12.5 years (mean 13.0, range 5-18). There were 24 men (mean age at presentation $\pm S D, 12.9 \pm 3.2$ years) and 19 women (mean age at presentation $\pm \mathrm{SD}, 13.0 \pm$ 2.9 years; $P=0.50)$. The majority of patients $(38,88 \%)$ were white; 3 were black, and 2 were Hispanic. The mean age at presentation ( $\pm S D$ ) of patients with adrenal tumours $(13.4 \pm 2.7$ years) was not significantly different from that of patients with extra-adrenal or multiple tumours (12.4 \pm 3.4 years), and that of patients with tumours which ultimately proved to be malignant $(13.0 \pm$ 3.4 years) was similar to that of patients with benign tumours $(12.9 \pm 2.4$ years). The interval between diagnosis and referral to our institutions ranged from 0 to 33.5 years (median 4.0 years). The patients had been followed-up for a median period of 6 years since diagnosis (range 1-34 years). Duration of follow-up was significantly longer for patients ultimately diagnosed as having malignant tumours (1-34 years, median 10.5 years) than for those thought to have benign tumours $(1-17$ years, median 4.5 years; $P=0.004$ ).

\section{Clinical features}

At least one of the symptoms classically associated with catecholamine excess - namely, hypertension (34 patients, $79 \%$ ), headache (19 patients, $44 \%$ ) and sweating (18 patients, $42 \%$ ) - were present in the majority of patients at presentation (Table 1). Hypertension was nonparoxysmal in the majority of cases, although two pa- 


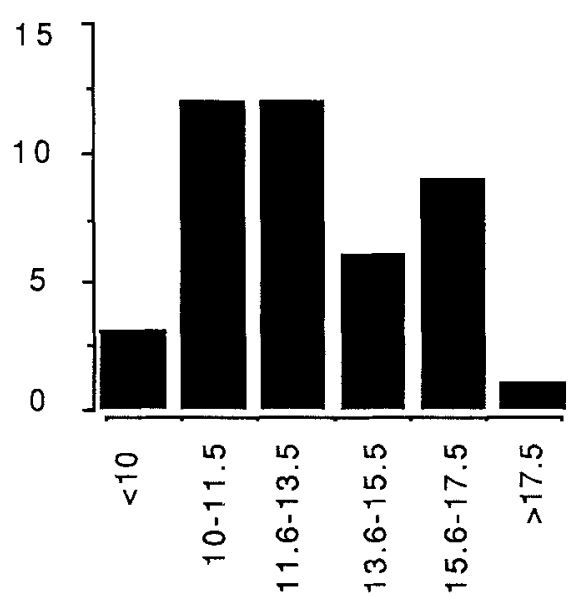

Fig. 1. Age at presentation (years)

tients presented in hypertensive crisis. The triad of hypertension, headache and sweating occurred in $10 \mathrm{pa}-$ tients $(23 \%)$.

One patient presented with congestive cardiac failure due to catecholamine cardiomyopathy which resolved after successful surgery for her phaeochromocytoma; she also had the triad described above. Her case is described in detail elsewhere (Imperato-McGinley et al. 1987). Four patients, all with malignant tumours, had erythrocytosis; all were hypertensive at presentation, and one is the subject of a recent case report (Shulkin et al. 1987). Four patients had neurological symptoms other than headache associated with hypertension: visual disturbance (2), encephalopathy (1) and gait disturbance (1).

Four patients had their tumours discovered incidentally. In one, a hypertensive black women, a benign paraganglioma of the organ of Zuckerkandl was discovered at age 17 during laparotomy for an abdominal mass which proved to be a leiomyosarcoma; 9 years later, she was found to have a malignant intrathoracic paraganglioma. This patient exhibited Carney's triad. Another patient, a normotensive white man, presented at the age of 13 years with abdominal pain and an enlarging pelvic mass; laparotomy disclosed a complex pelvic lymphangiomyoma and an incidental benign pelvic paraganglioma. His catecholamine levels remained elevated postoperatively, and he was subsequently found to have an additional benign juxta-adrenal paraganglioma as well as recurrent visceral lymphangiomyomatosis. This association has not, to our knowledge, been described previously. The patient is an adopted child, and his family history is unknown. In the third patient, a large mass apparently arising from the aortic bifurcation was noted during an appendectomy; palpation of this mass resulted in a dramatic rise in blood pressure - she had not previously been known to have hypertension. The last, asymptomatic patient with bilateral adrenal phaeochromocytomas was initially discovered at age 17 during biochemical screening of a kindred with Lindau-von Hippel disease; he developed skeletal and extradural metastases 19 years later.
Table 1. Clinical features

\begin{tabular}{|c|c|c|c|}
\hline & \multicolumn{2}{|c|}{ Final diagnosis } & \multirow[t]{2}{*}{ Total } \\
\hline & $\begin{array}{l}\text { Benign } \\
(n=17)\end{array}$ & $\begin{array}{l}\text { Malignant } \\
(n=26)\end{array}$ & \\
\hline \multicolumn{4}{|l|}{ Symptoms } \\
\hline Hypertension & 11 & 23 & 34 \\
\hline Headache & 8 & 11 & 19 \\
\hline Sweating & 8 & 10 & 18 \\
\hline $\operatorname{Triad}^{\mathrm{a}}$ & 4 & 6 & 10 \\
\hline Other: & 7 & 16 & 23 \\
\hline Polydipsia/polyuria & & & 4 \\
\hline Erythrocytosis & & & 4 \\
\hline Haematuria & & & 2 \\
\hline Tremor & & & 2 \\
\hline Visual disturbance & & & 2 \\
\hline Gait disturbance & & & 1 \\
\hline Encephalopathy & & & 1 \\
\hline Catecholamine cardiomyopathy & & & 1 \\
\hline Miscellaneous & & & 6 \\
\hline Delay in diagnosis $(n)$ & 6 & 3 & 9 \\
\hline Range (years) & $1-2$ & $2-8$ & $1-8$ \\
\hline \multicolumn{4}{|l|}{ Syndromes } \\
\hline \multicolumn{4}{|l|}{ Familial phaeochromocytoma: } \\
\hline Definite & - & 5 & 5 \\
\hline Possible & 2 & 1 & 3 \\
\hline$M E N-2 b$ & $1^{b}$ & 1 & 2 \\
\hline Neurofibromatosis & 1 & - & 1 \\
\hline Lindau-von Hippel & 1 & 1 & 2 \\
\hline Carney's triad & - & 1 & 1 \\
\hline
\end{tabular}

$M E N$, multiple endocrine neoplasia

a Hypertension + headache + sweating

b Bilateral adrenal medullary hyperplasia

Phaeochromocytomas were a manifestation of MEN-2b in 2 patients, Lindau-von Hippel disease in 2 (including the patient mentioned above) and neurofibromatosis in 1 . Five patients - all with malignant tumours - had a definite family history of phaeochromocytomas consistent with an autosomal dominant inheritance but not associated with neurocutaneous or MEN syndromes. Three additional patients ( 2 with benign and 1 with malignant tumours) had a possible family history, suggested by a history of hypertension and unexplained sudden death of a first-degree relative in young adulthood. Thus, at least 10 patients $(23 \%)$ - and possibly up to 13 - had phaeochromocytomas or functioning paragangliomas associated with an autosomal dominant, familial syndrome.

The diagnosis of phaeochromocytoma was made within 1 year of presentation in the majority of patients. There was a delay in diagnosis of $1-8$ years in 9 patients $(14 \%)$. 
Table 2. Plasma and urine biochemistry results

\begin{tabular}{|c|c|c|c|c|c|c|}
\hline Adrenaline $(\mathrm{pg} / \mathrm{ml})$ & $<100$ & 198 & 96 & 16 & 1157 & 43 \\
\hline Noradrenaline $(\mathrm{pg} / \mathrm{ml})$ & $<500$ & 7131 & 2661 & 205 & 54253 & 97 \\
\hline Noradrenaline $(\mu \mathrm{g} / 24 \mathrm{~h})$ & $<110$ & 872 & 530 & 24 & 4493 & 90 \\
\hline Metanephrine $(\mu \mathrm{g} / 24 \mathrm{~h})$ & $<85$ & 88 & 18 & 4 & 1043 & 21 \\
\hline Normetanephrine $(\mu \mathrm{g} / 24 \mathrm{~h})$ & $<165$ & 1113 & 212 & 6 & 9739 & 57 \\
\hline $\mathrm{VMA}(\mathrm{mg} / 24 \mathrm{~h})$ & $<7$ & 36 & 24 & 1.7 & 146 & 79 \\
\hline
\end{tabular}

VMA, vanillylmandelic acid

\section{Biochemical findings}

The results of plasma and urinary catecholamine and metabolite estimations are summarised in Table 2. There were no significant differences in any of these measurements between benign and malignant or between adrenal and extra-adrenal tumours. There were significant correlations between plasma and urinary noradrenaline $(r=$ $90, P<0.001)$, plasma adrenaline and noradrenaline $(r=$ $0.79, P<0.001)$ and urinary adrenaline and noradrenaline $(r=0.69, P<0.001)$ levels. Urinary VMA and total metanephrine levels correlated weakly $(r=0.39, P=$ 0.018 ). Only 1 patient had normal plasma and urinary biochemistry results; she was a 13-year-old girl with MEN-2b and surgically proven bilateral adrenal medullary hyperplasia detected by ${ }^{131} \mathrm{I}$-mIBG scan. No patient with abnormal urinary biochemistry data had normal plasma catecholamine levels. The 4 patients with normal urinary noradrenaline levels also had normal urinary adrenaline and metabolite levels, i.e. measurement of urinary metabolites did not improve the sensitivity of urinary catecholamine estimation. The combination of urinary VMA and normetanephrine estimations was a sensitive as measurement of urinary catecholamine excretion.

\section{Pathology}

Tumours arose in the adrenal glands in 24 patients (right adrenal in 10 , left adrenal in 6 , bilateral in 8 ); in 3 patients with bilateral adrenal tumours, the tumours were metachronous (Table 3). Nineteen patients had extra-adrenal or multiple (other than bilateral adrenal) tumours. The sites of presenting extra-adrenal tumours were periadrenal or perirenal in 6, para-aortic (including the organ of Zuckerkandl) in 6, the pelvis in 4 (including one bladder tumour), pericardiac in 1, paraspinal in 1 and multiple tumours at presentation in 1 (the patient described above). There were no significant sex differences between patients presenting with adrenal (13 men,
11 women) or extra-adrenal tumours (11 men, 8 women). Six patients with apparently solitary, benign tumours at initial operation went on to develop additional benign tumours ( 3 adrenal, 3 extra-adrenal), 1-16 years (median 3.3 years) later (Fig. 2).

Some 26 patients $(60 \%)$ ultimately proved to have malignant tumours. Malignancies were significantly more common among men (18) than women $(8 ; P=$ $0.028)$. Fourteen $(54 \%)$ of the malignancies occurred in patients who presented initially with primary adrenal tumours (bilateral in 3). Thus, malignancies were as likely to arise from adrenal $(14 / 24,58 \%)$ as from extraadrenal primaries $(12 / 19,63 \%)$. Only 15 tumours were obviously malignant at the time of initial diagnosis; the remainder were apparently benign but developed malignant local recurrences or distant metastases $0.5-26$ years after initial surgery (Fig. 2). Malignant behaviour was manifest as local spread in 23 , spread to lymph nodes in 15 and distant metastases to bone in 18 , lung in 8 , liver in 3 and other sites in 8 . Most patients with malignant tumours $(24,92 \%)$ developed multiple metastatic sites. Local recurrences of the primary tumour preceded more distant metastases in 4 patients by 2 ( 2 cases), 12 and 14 years. Four deaths were recorded at 2, 6, 14 and 30 years after initial presentation.

A record of the size of the presenting tumour was available for 33 patients $(77 \%)$, whose tumours ranged from 1.0 to $20.0 \mathrm{~cm}$ in maximum diameter (median $6.0 \mathrm{~cm}$; mean $\pm S D, 6.0 \pm 3.7 \mathrm{~cm}$ ). There was no significant difference in size between primary adrenal $(6.9 \pm$ $4.4 \mathrm{~cm}, n=19)$ and extra-adrenal tumours $(4.8 \pm 2.2 \mathrm{~cm}$, $n=14 ; P=0.125$ ). However, malignant tumours were significantly larger than benign ones $(7.4 \pm 4.1 \mathrm{~cm}, n=18$ vs. $4.3 \pm 2.3 \mathrm{~cm}, n=15$, respectively; $P=0.015$ ). Fifteen of 18 malignant tumours were $5 \mathrm{~cm}$ or more in maximum diameter, whereas 10 of 15 benign tumours were less than $5 \mathrm{~cm}$ in diameter $(P<0.01)$. All 10 malignant adrenal primaries were $\geq 5 \mathrm{~cm}$, while 7 of 9 benign adrenal phaeochromocytomas were $<5 \mathrm{~cm}(P<0.01)$; benign and malignant extra-adrenal tumours were of com- 
Table 3. Tumour location

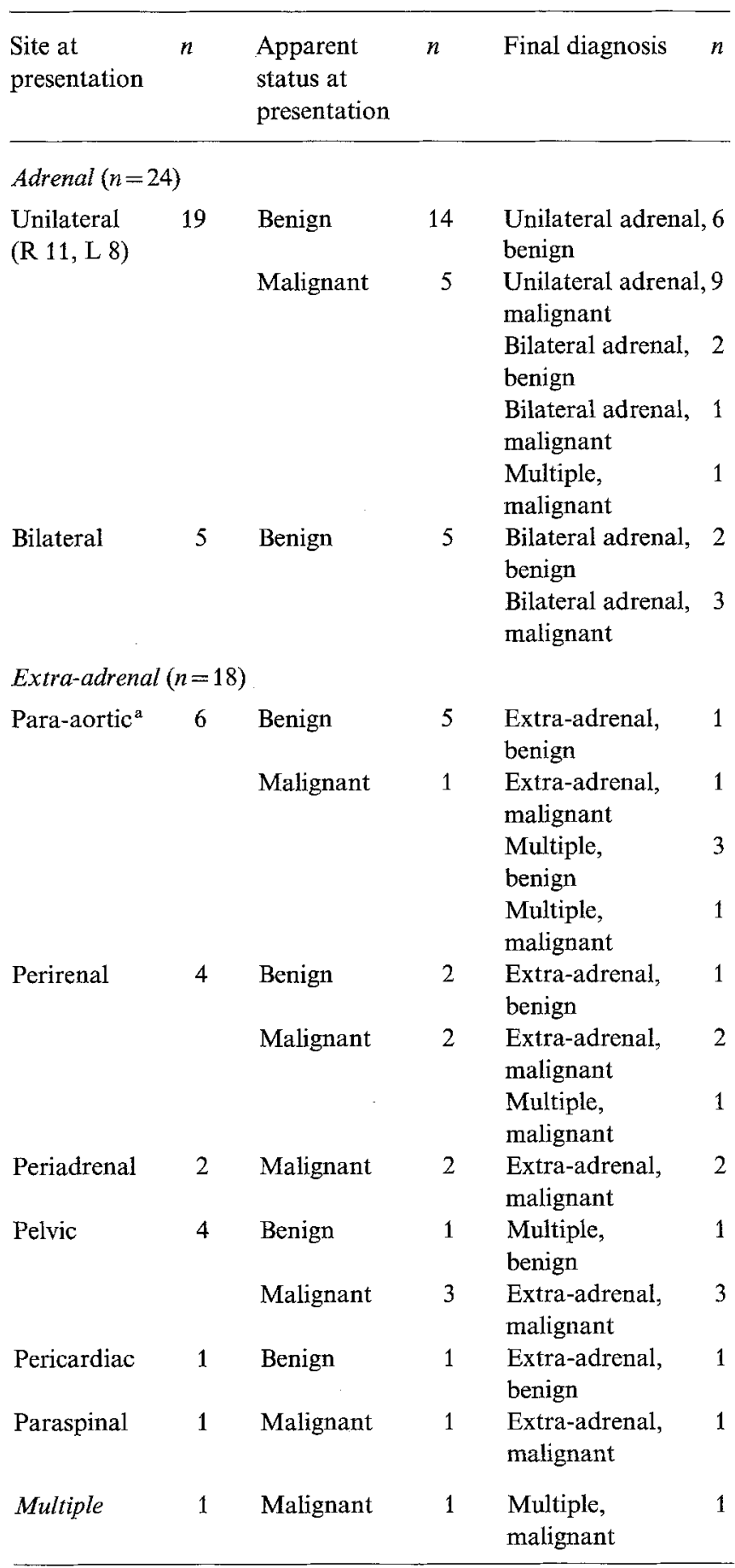

a Includes tumours arising in the organ of Zuckerkandl

parable size $(5 / 8$ malignant tumours $\geq 5 \mathrm{~cm}, 3 / 6$ benign tumours $<5 \mathrm{~cm}$ ).

There was no correlation between tumour size and plasma or urinary catecholamine or metabolite levels.

Role of ${ }^{131} I-m I B G$

The ${ }^{131} \mathrm{I}-\mathrm{mIBG}$ whole-body scan was true-positive in 33 patients (all known or subsequently proven sites of

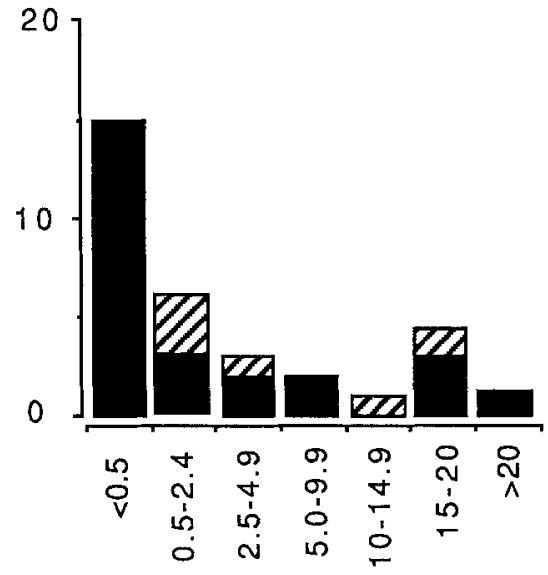

Fig. 2. Time to first metastasis (malignant tumours, black bars) or second tumour (benign tumours, hatched bars) since diagnosis (years)

Table 4. Tumour localisation by iodine 131 metaiodobenzylguanidine $\left({ }^{131} \mathrm{I}-\mathrm{mibg}\right)$ and computed tomography (CT) scanning

\begin{tabular}{lcc}
\hline & ${ }^{131} \mathrm{I}-\mathrm{mibg}$ & $\mathrm{CT}^{\mathbf{a}}$ \\
\hline True-positive $^{\mathbf{3}}$ & 33 & 27 \\
Equivocally positive $^{\mathbf{b}}$ & 3 & 3 \\
False-positive & 2 & 0 \\
True-negative & 0 & 2 \\
False-negative & 5 & 8 \\
\hline
\end{tabular}

a Three patients did not undergo CT scanning; 2 of these had true-positive ultrasound scans

b Detected some, but not all, subsequently proven disease foci

disease detected) (Table 4). Three of these patients had equivocal computed tomography (CT) scan findings and 6 had false-negative CT scans. (Three patients did not undergo CT study; 2 of them had positive results on ultrasound examination). Two patients had false-negative and 2 had equivocally abnormal venous sampling studies. ${ }^{131}$ I-mIBG scanning found some, but not all, sites of disease in a further 3 patients ("equivocally positive" studies) - bone metastases were missed in 2 patients and pulmonary metastases in 1 . All 3 had positive CT scans

Five patients had false-negative ${ }^{131} \mathrm{I}-\mathrm{mIBG}$ scans, 3 of whom had true-positive CT scans ( 2 of these 3 also had positive bone scans). One of the remaining 2 patients had a cervical disease focus located by venous sampling. The 5th patient, who was asymptomatic but had developed elevated catecholamine levels 3 years after excision of a paraganglioma of the right renal hilum, defied all attempts at localisation, including venous sampling, until 4 years later when he re-presented with a metastasis in L4 and cord compression.

Finally, 2 patients had apparently false-positive ${ }^{131} \mathrm{I}-$ mIBG scans. In 1, the scan suggested an abnormally increased right adrenal uptake in a patient who 5 years 
previously had an apparently benign tumour of the organ of Zuckerkandl but persistently elevated catecholamine levels and intermittent hypertension. The CT scan was negative, and vein sampling was equivocal; the adrenals appeared normal at re-exploration. The 2 nd patient developed hypertension and elevated catecholamine levels 16 years after resection of a paraganglioma of the organ of Zuckerkandl; the ${ }^{131}$ I-mIBG scan suggested that abnormalities were present in the left supraclavicular and left sacroiliac regions. This was not confirmed by subsequent $\mathrm{CT}$ scans, but an ultrasound examination suggested the presence of tumours at the junction of the left subclavian and jugular veins and adjacent to the left ovary. Exploration of the neck and thorax were negative; the pelvis was not explored.

Eight of the patients with malignant phaeochromocytomas received 1-5 therapeutic doses of ${ }^{131} \mathrm{I}-\mathrm{mIBG}$; the maximum total dose received was $44.6 \mathrm{GBq}$ $(1205 \mathrm{mCi})$. Three patients showed a partial response, 4 had no positive response (but no evidence of disease progression), and one had progressive disease and later died. ${ }^{131} \mathrm{I}-\mathrm{mIBG}$ therapy was never curative. Two patients have also received combination chemotherapy, with a partial response in 1 .

\section{Discussion}

Phaeochromocytomas and functioning paragangliomas are rare tumours of childhood and adolescence. Between 1954 and 1980, there were only 3 patients with phaeochromocytoma and 4 with paraganglioma recorded in the Manchester Childhood Tumour Registry (Birch 1983; Marsden 1983). This contrasts with an incidence of neuroblastoma of 168 ( 6.2 per million) and an overall prevalence of malignancies of 2688 (99.3 per million). Melicow (1977) reported 11 cases of childhood phaeochromocytoma/paraganglioma among 100 cases studied at a single institution. In the 20-year experience of over 500 hypertensive children at the Children's Hospital Medical Center, Cincinnati, Ohio (Loggie 1985) only 4 phaeochromocytomas, 1 adrenal ganglioneuroma and 1 brachial plexus paraganglioma were found. Similarly, the 20-year experience of the Toronto Hospital for Sick Children amounted to a total of 8 cases (Stringel et al. 1980), and the 30-year experience of the Mayo Clinic came to 18 cases aged 17 years or younger (Telander et al. 1985). At the Vanderbilt University Medical Center, only 2 of 69 patients with phaeochromocytoma were aged 18 years or less (Scott and Halter 1984). In their complete review of the world literature to 1962 , Stackpole et al. (1963) found a total of 91 cases of paediatric (symptom onset at age 15 years or younger) phaeochromocytoma (including extra-adrenal tumours) and added 9 cases of their own. Hume's (1960) earlier large review had found 85 published cases. The findings of these series, as well as our own, are summarised in Table 5. All of the larger series of phaeochromocytoma in childhood and adolescence thus far have emphasised the preponderance of affected males, the predominance of sustained rather than paroxysmal hypertension, the propensity for bilateral adrenal, extra-adrenal and multiple tumours and the possibility of familial occurrence.

It is obvious from Table 5 that the present series has an unusually high prevalence of malignant tumours; this is, at least in part, a reflection of referral bias, inasmuch as more "difficult" cases with suspected extra-adrenal or multi-focal (either metastatic malignant or multiple benign) disease were more likely to have been referred for tumour localisation with ${ }^{131}$ I-mIBG whole-body scintigraphy (see below). Nonetheless, it should be recalled that only $15(35 \%)$ of our patients were thought to have malignant tumours at the time of diagnosis (Table 3); the malignant potential of the tumours in the remaining 11 patients only became evident after a sometimes protracted follow-up. Similarly, 21 patients (49\%) had apparently solitary, benign tumours at presentation (14 adrenal, 7 extra-adrenal), but 6 of these (29\%) subsequently went on to develop additional benign tumours. The importance of (indefinite) follow-up of children or adolescents with phaeochromocytoma, in order to detect the later development of multi-focal or metastatic disease, has been emphasized by others (Stackpole et al. 1963; Kaufman et al. 1983). Scott and Halter (1984) have extended this recommendation to include all patients with phaeochromocytomas, since 5 of their 9 patients (aged 31-61 years) with malignant tumours were thought intially to have benign tumours but developed recurrent and/or metastatic disease 1-6 years after initial surgery. In a review of the early University of Michigan experience with ${ }^{131} \mathrm{I}$-mIBG, Beierwaltes (1987) estimated the cumulative incidence of detection of metastases of malignant phaeochromocytoma to be $5 \% /$ year for the first 9 years and $0.6 \% /$ year subsequently; metastases were present at diagnosis in only $47 \%$ of patients with malignant phaeochromocytoma. In the present series, since the duration of follow-up for patients with a "final" diagnosis of benign tumour was significantly shorter than for those with malignant tumours, it may be anticipated that the ultimate prevalence of malignancy will be even higher.

The patient's age at presentation or diagnosis, the clinical presentation (with the possible exception of erythrocytosis or the presence of unequivocal metastases), the biochemical findings and the location of the tumour with which the patient presented were not predictive of a subsequent malignant course. Men were found more commonly among patients with malignant tumours, and indeed male predominance appears to be a feature of most series of childhood phaeochromocytoma (Table 5), although the sex difference overall in the present series was not statistically significant. Large primary tumour size $(\geq 5 \mathrm{~cm})$ was significantly associated with malignan$\mathrm{cy}$, at least for adrenal tumours. Medeiros et al. (1985) also found malignant adrenal phaeochromocytomas to be significantly larger than benign tumours, and Scott 
Table 5. Comparison of present series with literature

\begin{tabular}{|c|c|c|c|c|c|c|c|}
\hline \multirow[b]{2}{*}{ No. of cases } & \multirow{2}{*}{$\begin{array}{l}\text { Hume } 1960 \\
85\end{array}$} & \multirow{2}{*}{$\begin{array}{l}\text { Stackpole et al. } \\
1963 \\
100\end{array}$} & \multirow{2}{*}{$\begin{array}{l}\text { Melicow } \\
1977 \\
11\end{array}$} & \multicolumn{2}{|c|}{$\begin{array}{l}\text { Kaufman et al. } 1983 \\
\text { (Telander et al. 1985) }^{\text {a }}\end{array}$} & \multirow{2}{*}{$\begin{array}{l}\text { Scott and } \\
\text { Halter } 1984 \\
8\end{array}$} & \multirow{2}{*}{$\begin{array}{l}\text { Present } \\
\text { study }\end{array}$} \\
\hline & & & & 16 & (18) & & \\
\hline Male:female & $52: 31$ & $68: 32$ & $7: 4$ & $" 2: 1$ " & & $7: 1$ & $24: 19$ \\
\hline Sustained hypertension & $\begin{array}{l}64 / 69 \\
93 \%\end{array}$ & $-\overline{88 \%}$ & - & $\begin{array}{l}9 / 12 \\
75 \%\end{array}$ & & $\begin{array}{l}4 / 8 \\
50 \%\end{array}$ & $\begin{array}{l}32 / 34 \\
94 \%\end{array}$ \\
\hline \multicolumn{8}{|l|}{ Tumor location } \\
\hline Solitary adrenal & $\begin{array}{l}36 / 76 \\
47 \%\end{array}$ & - & $\begin{array}{l}5 \\
45 \%\end{array}$ & $\begin{array}{l}6 \\
38 \%\end{array}$ & $(33 \%)$ & $\begin{array}{l}6 \\
75 \%\end{array}$ & $\begin{array}{l}15^{\mathrm{d}} \\
35 \%\end{array}$ \\
\hline Bilateral adrenal & $\begin{array}{l}18 / 76 \\
24 \%\end{array}$ & - & $\begin{array}{l}1 \\
9 \%\end{array}$ & $\begin{array}{l}3 \\
19 \%\end{array}$ & $(17 \%)$ & $\begin{array}{l}1 \\
12 \%\end{array}$ & $\begin{array}{l}8^{\mathrm{d}} \\
19 \%\end{array}$ \\
\hline Solitary extra-adrenal & $\begin{array}{l}11 / 76 \\
14 \%\end{array}$ & $19 \%$ & $\begin{array}{l}2 \\
18 \%\end{array}$ & $\begin{array}{l}4 \\
25 \%\end{array}$ & $\begin{array}{c}(6) \\
(33 \%)\end{array}$ & - & $\begin{array}{l}12^{\mathrm{d}} \\
28 \%\end{array}$ \\
\hline Multiple & $\begin{array}{l}11 / 76 \\
14 \%\end{array}$ & $-\overline{12 \%}$ & $\begin{array}{l}3 \\
27 \%\end{array}$ & $\begin{array}{l}3 \\
19 \%\end{array}$ & $(17 \%)$ & $\begin{array}{l}1 \\
12 \%\end{array}$ & $\begin{array}{l}8^{d} \\
19 \%\end{array}$ \\
\hline Malignant & $\begin{array}{l}3 / 85 \\
3.5 \%\end{array}$ & n.s. ${ }^{b}$ & $\begin{array}{l}1 \\
9 \%\end{array}$ & $\begin{array}{l}1 \\
6 \%\end{array}$ & $\begin{array}{l}(3) \\
(17 \%)\end{array}$ & $\begin{array}{l}1 \\
12 \%\end{array}$ & $\begin{array}{l}26 \\
60 \%\end{array}$ \\
\hline \multicolumn{8}{|l|}{ Syndromes } \\
\hline Familial phaeochromocytoma & 7 & $2 / 9^{\circ}$ & 3 & 2 & & - & 5 \\
\hline Neurofibromatosis & 1 & - & 1 & - & & - & 1 \\
\hline Lindau-von Hippel & - & - & - & - & & 2 & 2 \\
\hline MEN-2a & - & - & - & 2 & & 2 & - \\
\hline MEN-2b & - & - & - & 1 & & - & 2 \\
\hline Carney's triad & -- & - & - & - & & - & 1 \\
\hline
\end{tabular}

a Two additional cases reported in Telander et al. 1985. Numbers in parentheses include these 2 cases

b Not specified

c Two of the authors' 9 additional cases were siblings

¿ Final diagnosis

and Haiter (1984) noted that all their malignant tumours were $\geq 6 \mathrm{~cm}$ in diameter.

Because of the nature of the present series, no meaningful estimate can be made of the sensitivity or specificity of the diagnostic or localising procedures used. Nevertheless, it may fairly be concluded (Table 2) that plasma and urinary noradrenaline estimations are the most useful diagnostic biochemical measurements; neither urinary metanephrine levels nor urinary VMA levels in isolation were as frequently positive as plasma or urinary catecholamine (specifically, noradrenaline) levels. These findings are somewhat at odds with the recent Mayo Clinic data in children (Kaufman et al. 1983) but consistent with those of Bravo and Gifford (1984) for phaeochromocytomas in general.

An iodinated aralkylguanidine, $\mathrm{mIBG}$ is structurally similar to guanethidine and noradrenaline and is taken up into the adrenal medulla and similar tissue by the neuronal catecholamine reuptake mechanism and is stored in catecholamine storage vesicles (Wieland et al. 1981). Its application in the localisation of phaeochromocytomas, paragangliomas, neuroblastomas and other tumours of putative neural crest origin has been the sub- ject of several recent reviews (Shapiro et al. 1985, 1989; McEwan et al. 1985; Mauer and Mastrangelo 1987; Shapiro and Sisson 1988). The overall accuracy of mIBG scintigraphy for tumour localisation in the present series is comparable with that recorded elsewhere in the literature. The false-negative rate for CT scanning $(20 \%)$ was higher than that for mIBG scanning $(12 \%)$. Whole-body scanning with mIBG has been shown to be superior to CT scanning for the localisation of extra-adrenal, multifocal and metastatic malignant phaeochromocytomas and paragangliomas (reviewed in McEwan et al. 1985; Shapiro et al. 1989).

The somewhat disappointing results of ${ }^{131} \mathrm{I}-\mathrm{mIBG}$ therapy in this group of patients is consistent with our overall experience in 28 patients with malignant phaeochromocytomas (Shapiro and Sisson 1988), at least 8 of whom showed partial objective responses ( 5 of these subsequently relapsed), 10 had stable disease, and 10 suffered from progressive disease. The results of ${ }^{131} \mathrm{I}$-mIBG therapy for neuroblastoma are a little better (Mauer and Mastrangelo 1987; Shapiro and Sisson 1988; Shapiro et al. 1989), possibly reflecting the relatively greater radiosensitivity of neuroblastomas. 
In conclusion, phaeochromocytomas and functioning paragangliomas are rare tumours of childhood and adolescence. Unlike their adult counterparts, affected children present more commonly with sustained rather than paroxysmal hypertension and more usually have bilateral adrenal, extra-adrenal or multi-focal tumours. The prevalence of malignant tumours has probably been underestimated in the past. The need for lifelong followup is underscored since patient and tumour characteristics at presentation (other than primary tumour size $\geq 5 \mathrm{~cm}$ for adrenal tumours) are poor predictors of the later development of multi-centric or malignant disease. The usual biochemical tests (particularly plasma and urinary catecholamine levels) appear to be as diagnostically reliable as in the adult population. Whole-body scintigraphy with ${ }^{131} \mathrm{I}-\mathrm{mIBG}$ is an effícacious, non-invasive, localising procedure, particularly for extra-adrenal, multi-focal or metastatic malignant tumours. ${ }^{131} \mathrm{I}-\mathrm{mIBG}$ therapy has a limited role but may be considered as a palliative measure when alternatives have failed.

\section{References}

Beierwaltes WH (1987) Clinical applications of ${ }^{131}$ I-labelled metaiodobenzylguanidine. In: Hoffer PB, Gore JC, Gottschalk A, Sostman D, Zaret BL (eds) Year book of nuclear medicine, 1987. Year Book Medical Publishers, Chicago, pp 17-34

Birch JM (1983) Epidemiology of paediatric cancer. In: Duncan W (ed) Recent results in cancer research, vol 88: paediatric oncology. Springer, Berlin Heidelberg New York, pp 1-10

Bravo EL, Gifford RW (1984) Pheochromocytoma: diagnosis, localization and management. N Engl J Med 311:1298-1303

Carney JA (1983) The triad of gastric epithelioid leiomyosarcoma, pulmonary chondroma, and functioning extra-adrenal paraganglioma: a five-year review. Medicine (Baltimore) 62:159169

Glenner GG, Grimley PM (1974) Tumors of the extra-adrenal paraganglion system (including chemoreceptors). Atlas of tumor pathology, 2nd series, fascicle 9. Armed Forces Institute of Pathology, Washington DC, pp 13-15

Glowniak JV, Shapiro B, Sisson JC, Thompson NW, Coran AG, Lloyd RV, Kelsch RC, Beierwaltes WH (1985) Familial extraadrenal pheochromocytoma: a new syndrome. Arch Intern Med 145:257-261

Hume DM (1960) Pheochromocytoma in the adult and in the child. Am J Surg 99:458-496

Imperato-McGinley J, Gautier T, Ehlers K, Zullo MA, Goldstein DS, Vaughan ED (1987) Reversibility of catecholamine-induced dilated cardiomyopathy in a child with pheochromocytoma. N Engl J Med 316:793-797

Kaufman BH, Telander RL, van Heerden JA, Zimmerman D, Sheps SG, Dawson B (1983) Pheochromocytoma in the pediatric age group: current status. J Pediatr Surg 18:879-884

Loggie JMH (1985) Evaluation and management of childhood hypertension. Surg Clin North Am 65:1623-1649

Manger WM, Gifford RW (1982) Hypertension secondary to pheochromocytoma. Bull NY Acad Med 58:139-157

Marsden HB (1983) The pathology and natural history of childhood tumours. In: Duncan W (ed) Recent results in cancer research, vol 88: paediatric oncology. Springer, Berlin Heidelberg New York, pp 11-25
Mauer AM, Mastrangelo R (eds) (1978) Symposium: the role of MIBG in therapy, diagnosis and monitoring of neuroblastoma. Med Pediatr Oncol 15:157-228

McEwan AJ, Shapiro B, Sisson JC, Beierwaltes WH, Ackery DM (1985) Radioiodobenzylguanidine for the scintigraphic localization and therapy of adrenergic tumors. Semin Nucl Med $15: 132-153$

Medeiros LJ, Wolf BC, Balogh K, Federman M (1985) Adrenal pheochromocytoma: a clinicopathological review of 60 cases. Hum Pathol 16:580-589

Melicow MM (1977) One hundred cases of pheochromocytoma (107 tumors) at the Columbia-Presbyterian Medical Center, 1926-1976. Cancer 40:1987-2004

Nakajo M, Shapiro B, Copp J, Kalff V, Gross MD, Sisson, JC, Beierwaltes WH (1983) The normal and abnormal distribution of the adrenomedullary imaging agent $m$-[I-131] iodobenzylgunanidine (I-131 MIBG) in man: evaluation by scintigraphy. J Nucl Med 24:672-682

Peuler JD, Johnson GA (1977) Simultaneous single isotope radioenzymatic assay of plasma norepinephrine, epinephrine and dopamine. Life Sci $21: 625-636$

Pisano JJ, Crout J, Abraham D (1962) Determination of 3-methoxy, 4-hydroxy-mandelic acid in urine. Clin Chim Acta 7:285-291

Scott HW, Halter SA (1984) Oncologic aspects of pheochromocytoma: the importance of follow-up. Surgery 96:1061-1066

Shapiro B, Fig LM (1989) Management of pheochromoytoma. Endocrinol Metab Clin North Am 18:443-481

Shapiro B, Sisson JC (1988) Sympathoadrenal imaging with radioiodinated metaiodobenzylguanidine. In: Van Nostrand D, Baum S (eds) Atlas of nuclear medicine. Lippincott, Philadelphia, pp 72-114

Shapiro B, Sisson JC, Kalff V, Glowniak JV, Satterlee WG, Glazer GM, Francis IR, Bowers R, Thompson NW, Orringer M, Beierwaltes WH (1984) The location of middle mediastinal pheochromocytomas. J Thorac Cardiovasc Surg 87:814 820

Shapiro B, Copp JE, Sisson JC, Eyre PL, Wallis J, Beierwaltes WH (1985) Iodine-131 metaiodobenzylguanidine for the location of suspected pheochromoytomas: experience in 400 cases. J Nucl Med 26:576-585

Shapiro B, Fig LM, Gross MD, Khafagi F (1989) Radiochemical diagnosis of adrenal disease. CRC Crit Rev Clin Lab Sci 27:265-298

Shulkin BL, Shapiro B, Sisson JC (1987) Pheochromocytoma, polycythemia, and venous thrombosis. Am J Med 83:773-776

Shulkin BL, Sisson JC, Koral KF, Shapiro B, Wang X, Johnson $J$ (1988) Conjugate-view gamma camera method for estimating tumor uptake of iodine-131 metaiodobenzylguanidine. J Nucl Med 29:542-548

Stackpole RH, Melicow MM, Uson AC (1963) Pheochromocytoma in children: report of 9 cases and review of the first 100 published cases with follow-up studies. J Pediatr $63: 315-330$

Stringel G, Ein SH, Creighton R, Daneman D, Howard N, Filler RM (1980) Pheochromoytoma in children - an uptade. J Pediatr Surg 15:496-500

Telander RL, Zimmerman D, Kaufman BH, van Heerden JA (1985) Pediatric endocrine surgery. Surg Clin North Am 65:1551-1587

Von Euler US, Lishajko F (1959) Estimation of catecholamines in urine. Acta Physiol Scand 45:122-132

Wieland DM, Brown LE, Tobes MC, et al. (1981) Imaging the primate adrenal medulla with $1-123$ and 1-131-meta-iodobenzylguanidine. J Nucl Med 22:358-364 